\title{
Sobre a necessidade de legitimar as práticas de atenção primária
}

\author{
On the need to legitimate primary care practices
}

Eleonor Minho Conill ${ }^{1}$

'Doutora em Desenvolvimento Econômico e Social pela Université Paris I Panthéon-Sorbonne - Paris, França; Professora adjunta do Departamento de Saúde Pública da Universidade Federal de Santa Catarina (UFSC) Florianópolis (SC), Brasil. eleonorconill@gmail.com
$\mathrm{M}$ esmo com idas e vindas, a atenção primária tem perpassado décadas de reformas, num movimento cíclico e aparentemente pendular. $\mathrm{O}$ texto de Mario Rovere resgata muito bem essa história trazendo elementos sobre a conjuntura na qual o termo foi cunhado e o contexto de ajustes macroeconômicos que explica, apenas em parte, os retrocessos nos objetivos na famosa Saúde Para Todos/2000 (SPT/2000). Gostaria de iniciar minha contribuição neste debate sugerindo alguns elementos complementares acerca dessa trajetória.

O autor mostra como as propostas de Atenção Primária à Saúde (APS) incorporaram diversas tradiçóes do campo da saúde coletiva, tão antigas quanto à polícia médica e à prestação integrada de serviços locais para populaçóes pobres. É interessante lembrar o título provocativo Community medicine under imperialism: a new medical policy? de um artigo publicado por Jaime Breilh (1979).

Estávamos na época da guerra contra a pobreza do governo Lindon Jonhson e de projetos extramuros dos Departamentos de Medicina Preventiva norte-americanos. Foram experiências que atravessaram fronteiras, assumindo diversas conotaçóes desde projetos contra-hegemônicos de saúde comunitária na América Latina até as Clínicas Populares em Montreal. O contexto do pós-guerra havia favorecido uma expansão importante da cobertura de serviços (e do complexo médico-industrial) nos países centrais, que começavam a pesar nas contas públicas. A retomada das propostas 'dawsonianas' de uma organização de serviços a partir de uma área definida com centros locais de saúde e hierarquizaçáo dos cuidados vai compor um discurso de racionalização que passa a circular com maior intensidade a partir da década de 1960.

Com base na revisão de diversas reformas que ocorreram a partir desse período, formulamos uma hipótese que coincide com o quadro síntese proposto no texto, o qual fornece uma interessante representação gráfica de seus principais componentes. O conteúdo desse discurso representava respostas a necessidades de ordem econômica, política e social, mas também respondia a demandas oriundas dos próprios movimentos sociais e setoriais existentes nesse contexto. De um lado, um polo tecnocrático propondo a incorporação de medidas inovadoras e de racionalização das práticas (comunidade como fundamento das necessidades de saúde, hierarquização, coordenação e integraçáo do cuidado) e, de outro, um polo participativo, associado a uma maior democratizaçáo dos serviços (mudanças na divisão do saber/poder, com ampliação da equipe, incorporação de agentes da comunidade, acesso e controle social). O estudo das diversas conjunturas ou contextos de aplicaçáo permitiria 
identificar seus elementos principais, combinações ou a direção predominante (CONILL; O’NEILL, 1984).

Como sabemos, esse discurso informou, de distintas maneiras e com diferentes graus de intensidade, processos de reforma em formaçóes sociais com sistemas de saúde tão diversos quanto Cuba, Moçambique, Canadá, Inglaterra, Espanha e Brasil, para citar alguns exemplos. Passadas algumas décadas, a APS retorna à cena num contexto de reformas pró-coordenação. A racionalização continua sendo o principal leimotiv; no entanto, mais do que apostar no controle social ou na participação para adequar os serviços às necessidades, $\mathrm{o}$ novo discurso se apoia na qualidade e na continuidade da atenção.

Evidentemente que é necessário distinguir o que pode ser um imperativo de racionalidade para o sucesso do mercado (managed care) ou uma necessidade para tornar o acesso oportuno e diminuir desigualdades, como é o caso dos sistemas nacionais. Mas, não vejo nisso um problema maior (o que não significa negar sua importância). Todos que acompanham as experiências de participação sabem as inúmeras contradiçóes que perpassam as diversas modalidades que foram empreendidas com dificuldades operacionais e predomínio de um uso instrumental ou político.

Num texto com tantas perguntas importantes, vou me ater a dois parágrafos quase ao final do trabalho:

La de-construcción de la APS es una tarea imprescindible para perfilarla como una herramienta de transformación social en los tiempos que corren. El contexto de crisis económica y desconcierto político de los paises centrales, el fracaso - por mérito propio - de los organismos internacionales de crédito, el surgimiento de nuevas experiencias sociales y politicas en la mayor parte de los paises de América Latina son elementos útiles pero no suficientes como para apenas agregarle algún 're' ('re' vitalización, 're' lanzamiento, ....) a la APS.

Parece necesario evaluar sus principales componentes, despejar sus equivocos, des-idealizar sus enunciados, enfrentar todo intento de canibalizar su terminología, armar campos de fuerza en donde quede claro cuales son los actores y como se posicionan respecto al derecho a la salud, a la inclusión social y a profundizar la equidad, desarrollar estrategias en consecuencia y pensar nuevas reglas de juego.

Tenho refletido sobre a necessidade de realizar uma separação analítica entre os níveis macro (formulação de políticas), meso (gestão) e micro (prestação direta de serviços). Embora esses níveis estejam inter-relacionados, separá-los permite identificar e compreender melhor as distintas lógicas de interação e ação social que implicam estratégias particulares de mudança.

Em nível macrossocial ocorrem decisões políticas que incidem sobre os direitos de acesso, no financiamento e nas intervenções sobre determinantes sociais, expressando interesses econômicos, políticos e culturais, conforme cada conjuntura e formação social. São resultados de processos históricos e sociais que envolvem muitas mediaçóes e atores e, o mapeamento de posições sugerido ao final do parágrafo, se aplica muito bem a esse nível analítico.

Numa análise dessa ordem teríamos algumas surpresas com as medidas empreendidas na sucessáo dos últimos governos progressistas no Brasil. Houve uma expansão significativa da Estratégia da Saúde da Família com medidas recentes na direção de melhoria do acesso e da qualidade. Porém, o financiamento privado ainda excede o público, numa contradição crucial com os princípios de construção do Sistema Único de Saúde (SUS), o que tem sido permanentemente apontado pelo movimento sanitário (SANTOS; AMARANTE, 2011). Atualmente, o sistema de saúde brasileiro é um sistema universal com uma cobertura duplicada e desigual: enquanto a população de renda mais baixa utiliza o SUS, os usuários do segmento suplementar podem constitucionalmente recorrer aos dois, com direito à renúncia fiscal. E isto se dá para alguns exames, procedimentos mais sofisticados e medicamentos mais custosos criando-se uma situação em que o SUS é que se torna suplementar para os que possuem plano privado, cuja cobertura se aproxima aos $50 \%$ em algumas capitais da regiáo sul e sudeste. 
Mesmo em cidades consideradas com um bom desempenho das equipes de saúde da família, esse padrão se repete.

As explicaçóes para essa situação são certamente complexas e estão ancoradas na heterogeneidade estrutural que marca o país, numa reforma inconclusa do ponto de vista político e nos traços de uma cultura marcada por um agir particularista. Mas, convém refletirmos um pouco mais sobre os processos de prestação de cuidado no plano microssocial.

Num recente Seminário da Rede de Pesquisa em APS, realizado em Brasília em abril de 2012, a intervenção feita por um conhecido pesquisador da área me pareceu pertinente. Ao introduzir um trabalho qualitativo realizado num município de Sáo Paulo, alertava para o fato de termos cautela uma vez que o SUS era um sistema que não usávamos, mas para o qual nos dirigíamos com uma carga muito grande de idéias (no sentido de idealizações).

Ideais regulatórios são contrapontos necessários a um pragmatismo utilitarista, mas o equilíbrio é difícil. Parece imprescindível olhar com cuidado o que vem da prática com foco nas demandas locais, muitas vezes imediatas e absolutamente clínicas.

Foi nessa linha a conclusão de uma avaliação externa promovida pela Sociedade Brasileira de Medicina de Família e Comunidade (GÉRVAS; FERNÁNDEZ, 2011). Os pesquisadores desse trabalho realizaram visitas a 70 equipes de saúde da família, entrevistando um número expressivo de profissionais em 19 Estados do país. O relatório destaca os efeitos positivos sobre as desigualdades por sua implantaçáo nas áreas de baixo índice de desenvolvimento humano, impacto nas hospitalizaçóes evitáveis, existência de uma equipe ampliada com agentes comunitários, além de um apoio sustentado da gestão federal, estadual e municipal.

$\mathrm{O}$ ponto negativo advém do modo como esse apoio se expressa na prestação direta dos serviços: rotatividade de profissionais pela ausência de planos de carreira, baixa densidade tecnológica, preponderância dos programas verticais com um 'déficit curativo' além de um excesso de protocolos que enrijecem a prática. É uma expressão que o autor usa mas não estou citando a frase na íntegra, acho que dá para tirar as aspas que resolve.

Os atributos da APS possibilitam um cuidado integral com menor consumo num setor no qual a especialização garante uma enorme acumulação de capital. A disputa é acirrada sendo, portanto, crucial não descuidarmos de sua legitimação e credibilidade na prática. Trata-se de uma tarefa complexa, pois é necessário lidar com uma aparente contradição: ao mesmo tempo, em que se pretende construir saúde é necessário responder à doença de modo adequado. E isto, na maior parte das vezes, com recursos escassos e instáveis. Mas, este é um desafio que considero central ao debate.

\section{Referências}

BREILH,J. Community medicine under imperialism: a new medical policy? International Journal of Health Services, Baltimore, v. 9, n. 5, 1979 , p. 5-24.

CONILL, E.M.; O'NEILL, M. La notion de santé communautaire: éléments de comparaison internationale. Canadian Journal of Public Health, Ottawa, v. 75, 1984, p. 166-175.

GÉRVAS, J.; FERNÁNDEZ, M.P. É possível transformar o círculo vicioso de má qualidade em um círculo virtuoso de boa qualidade no trabalho clínico e comunitário na atenção primária no Brasil. Relatório de Pesquisa, SBMFC. Disponível em: <http://www. sbmfc.org.br/default.asp?site_Acao=MostraPagina\&Pagina ld =524>. Acesso em: 24 jul. 2012.

SANTOS, N.R.; AMARANTE, P.D.C. (Org). Gestão pública e relação público privado na saúde. Rio de Janeiro: CEBES, 2011. 